\title{
Polyethylene Failure of the Patellar Component in New Jersey Low-Contact Stress Total Knee Arthroplasties
}

\author{
Chun-Hsiung Huang, MD, ${ }^{*} \dagger$ Jiann-Jong Liau, PhD, $\dagger$ Fang-Yuan Ho, MS $\neq \ddagger$ \\ Chia-Yin Lin, BS, $\ddagger$ Tai-Horng Young, PhD, $\S$ and Cheng-Kung Cheng, PhD $\dagger$
}

\begin{abstract}
In a postoperative 5- to 12-year follow-up study of 598 New Jersey lowcontact stress total knee arthroplasties, 32 required revision. All retrieved patellar components were examined for polyethylene damage. These 32 cases had 3 types of failure: split rupture (7 cases), peripheral wear (21), and cantilevering breakage (4), respectively $75 \%, 64.3 \%$, and $100 \%$ of which showed subluxation and/or tilting of the patellar component on the prerevision roentgenograms. Misalignment at the joint contact surfaces and rotational blockage of the mobile patellar component were considered the major causes of the failure. A design of a flatter metallic button (giving larger focal thickness of the polyethylene) and a dome-shaped polyethylene (reducing stress concentration at the pinnacle) may alleviate the failure driving mechanism should subluxation or tilting of the patellar component take place. Key words: patellar component failure, low-contact stress, total knee arthroplasty.

(C) 2005 Elsevier Inc. All rights reserved.
\end{abstract}

The New Jersey low-contact stress (LCS; DePuy, Warsaw, Indiana) knee system was introduced in the late 1970s by Buechel and Pappas [1]. It was designed to minimize stress on the bearing surface and at the implant/bone interface. After the advent of solutions for implant loosening, polyethylene wear has become the major long-term complication of total knee arthroplasties. In our previous study, we reported 8 cases of severe symptomatic tibial

From the *Department of Orthopaedic Surgery, Mackay Memorial Hospital, Taipei, Taiwan; †Orthopaedic Biomechanics Laboratory, Institute of Biomedical Engineering, National Yang Ming University, Taipei, Taiwan; $\ddagger$ Biomechanics Research Laboratory, Department of Biomedical Research, Mackay Memorial Hospital, Taipei, Taiwan and §Institute of Biomedical Engineering, National Taiwan University, Taipei, Taiwan.

Submitted December 27, 2001; accepted August 18, 2004. No benefits or funds were received in support of the study. Reprint requests: Chun-Hsiung Huang, MD, Department of Orthopaedic Surgery, Mackay Memorial Hospital, No. 92, Sec. 2, Chung-San North Road, Taipei, Taiwan.

(c) 2005 Elsevier Inc. All rights reserved.

$0883-5403 / 04 / 2002-0010 \$ 30.00 / 0$

doi:10.1016/j.arth.2004.08.001 polyethylene failure in LCS arthroplasties with meniscal bearing [2]. In this study, we focused on the polyethylene failures of patellar components in the LCS knee system.

The patellar component of the LCS design has been renowned for its congruent anatomic shape and rotational mobility. The features of this design include a rotating bearing attached to a thin metallic anchoring plate fixed to the bone by cruciform fixation fin. Buechel et al reported an 11-year clinical study of such metal-backed, rotating-bearing patellar prostheses [3]. They reported 3 cases (out of 515, a rate of $0.6 \%$ ) of complications that required revision surgery, including 1 intraoperative vertical midpatellar fracture and 2 displaced postoperative transverse midpatellar fractures, but no polyethylene wearthrough, no separation from the metal anchoring plate, nor implant breakage. On the other hand, in Sorrells's study of the LCS rotating-platform total knee prosthesis [4], no patellar polyethylene wear was reported. However, several different types of polyethylene damage were found in the retrieved patellar components of the 32 failed 


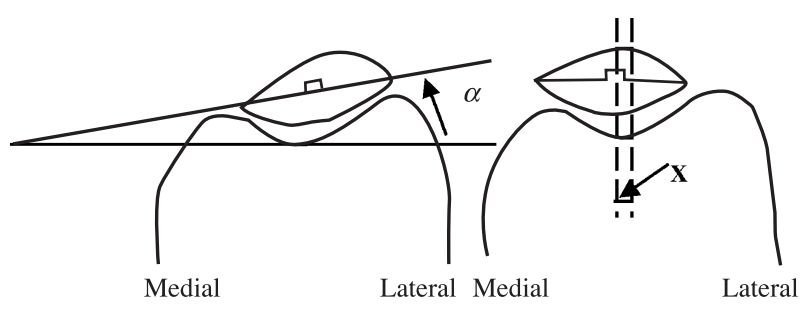

Fig. 1. Gomes/Bindelglass modified roentgenographic measurements of patellar tilt angle $(\alpha)$ and displacement from the center of the trochlear groove $(\times)$.

cases in this study. The focus of this study was on the classification of these types of patellar polyethylene failure as well as the investigation of the failure mechanisms.

\section{Material and Methods}

From 1985 to 1990, 598 New Jersey LCS total knee arthroplasties were performed at our hospital by or under the direct supervision of the same senior surgeon. Among them, the rotating platform was used in 322 knees and the meniscal bearing in 276 knees. All the patellar components were metal-backed rotating bearing. In this 5- to 12 -year study, 32 knees required revision surgery, 21 of which were directly attributed to the patellar component.

Roentgenograms were taken before the revision with a $45^{\circ}$ Merchant view. In the retrieval analysis, the wear pattern as well as location was examined to investigate the relationship between the wear pattern and the patellar alignment. The patellar tilt and subluxation in the Merchant view were measured by the method proposed by Gomes et al [5], with modifications suggested by Bindelglass et al [6], in which the reference line was drawn tangentially to the floor of the trochlear groove rather than between the high points of the asymmetric flanges (Fig. 1). This method was used to quantify the condition of the patellar tracking in the center of the trochlear groove. A "good" tracking condition was defined when the lateral-medial tilt was less than $5^{\circ}$, and the subluxation displacement was less than $5 \mathrm{~mm}$ at the same time. The surfaces or cross sections of the failed polyethylene were examined by scanning electron microscopy (S-3500N, Hitachi, Japan) to investigate the failure mechanism.

\section{Results}

The revisions of the 32 knees include 1 case of femoral component fracture and 31 cases of severe polyethylene wear in the tibial and/or patellar components. Among the latter 31 cases, 10 cases were revised primarily for tibial component failure, 11 cases were primarily for patellar component failure, and 10 cases were for both tibial and patellar component failures. The overall failure rate of the LCS design in our retrieval analysis was $5.35 \%(32 / 598)$, whereas the incidence of revision due to patellar failure was $3.5 \%$ (21/598).

The 32 retrieved patellar components were classified into 3 groups according to the type of polyethylene damage.

\section{Group A-Split Rupture}

Among the 32 retrieved components, 7 (21.87\%) had a straight splitting crack found along the
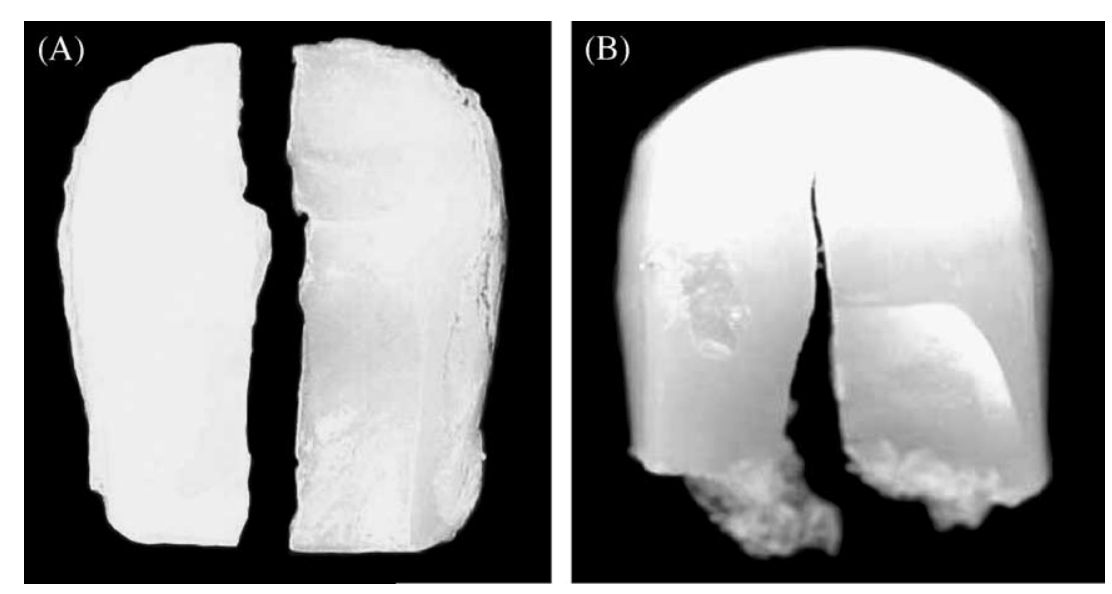

Fig. 2. Two types of polyethylene failure in group A. (A) Zip-through crack. (B) Developing crack. 

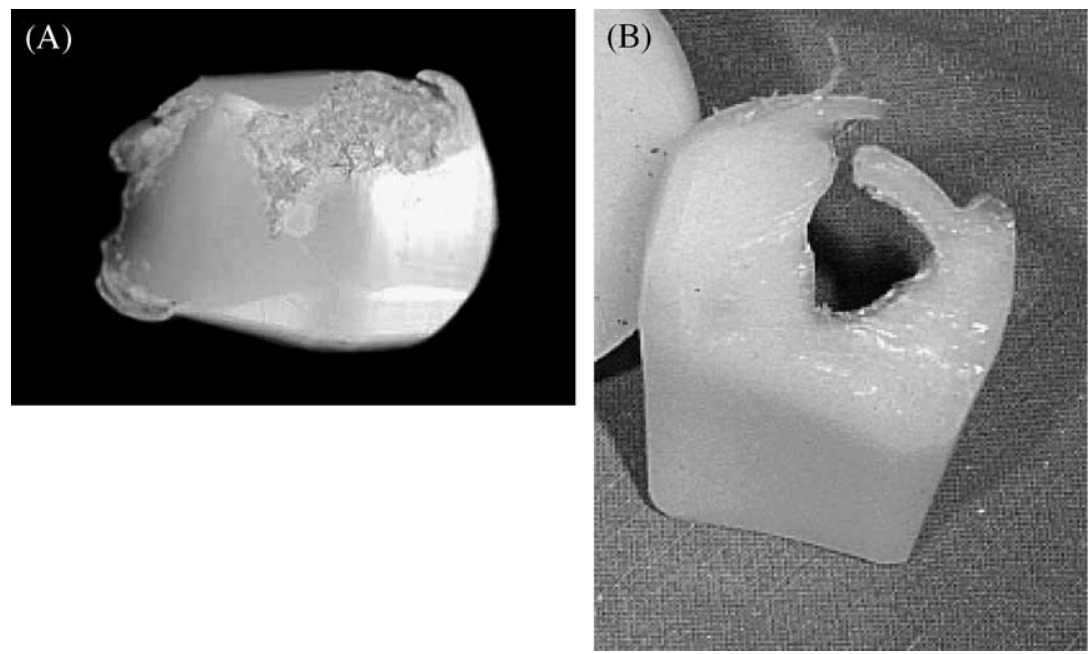

Fig. 3. (A) Peripheral wear seen in group B. (B) A worn-through polyethylene in the medial portion.

transverse central line of the polyethylene. Among these 7 cases, 4 had the polyethylene portion split into 2 symmetrical parts (Fig. 2A), whereas the remaining 3 samples showed a partial split with a developing crack (Fig. 2B). The crack lines always occurred in the region where the polyethylene was thin, either beneath the metallic button or its lateral portion. The thicker region of the medial portion seemed to be able to arrest the crack
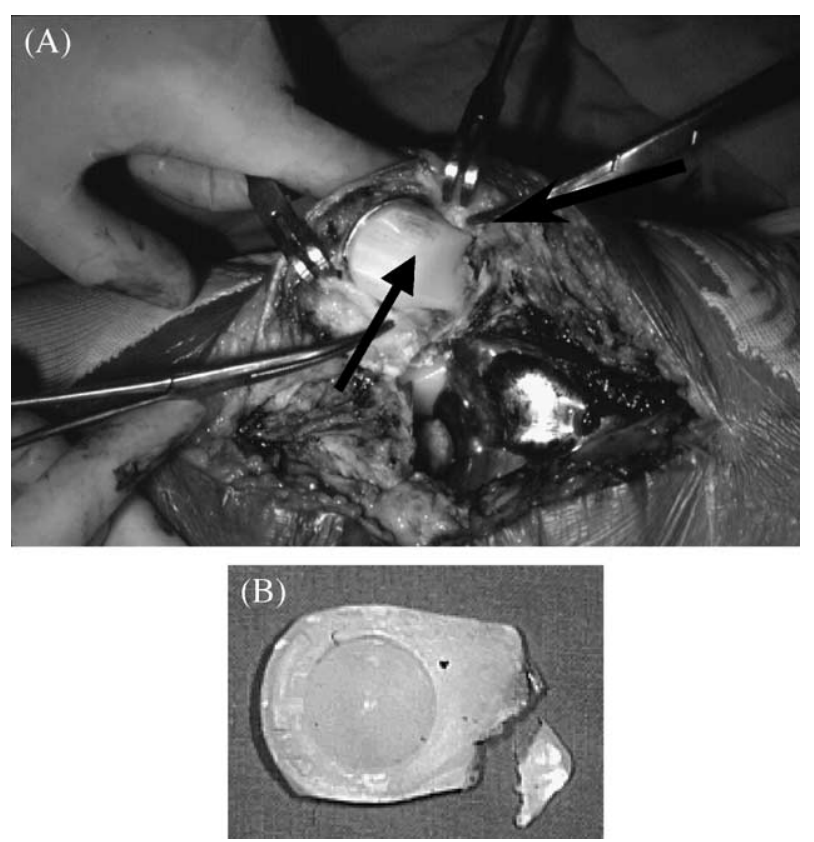

Fig. 4. (A) Bony ingrowth over the corner of the metal plate was found during surgery. (B) Breakage of the cantilevering edge. propagation starting from the thin region in the cases of a partial split.

\section{Group B-Peripheral Wear}

There were 21 cases $(65.63 \%)$ showing wear around peripheral regions (Fig. 3A). Wear patterns ranged from slight scratch to severe wear, which may be accompanied with color change, and were identified by visual inspection. Regardless of the degree of wear, most polyethylene components showed a similar wear location, visible at the periphery but occasionally extending to the patellar ridge. Among these 21 cases, 1

Table 1. Results of the Roentgenogram Measurement in Each Group

\begin{tabular}{|c|c|c|c|c|c|c|}
\hline \multirow[b]{2}{*}{ Item } & \multicolumn{2}{|r|}{ Group A } & \multicolumn{2}{|r|}{ Group B } & \multicolumn{2}{|r|}{ Group C } \\
\hline & $\begin{array}{l}\text { Tilt } \\
\left({ }^{\circ}\right)\end{array}$ & $\begin{array}{l}\text { Subluxation } \\
(\mathrm{mm})\end{array}$ & $\begin{array}{l}\text { Tilt } \\
\left({ }^{\circ}\right)\end{array}$ & $\begin{array}{l}\text { Subluxation } \\
(\mathrm{mm})\end{array}$ & $\begin{array}{l}\text { Tilt } \\
\left(^{\circ}\right)\end{array}$ & $\begin{array}{l}\text { Subluxation } \\
(\mathrm{mm})\end{array}$ \\
\hline 1 & 4 & 5 & 15 & 9 & 10 & 8 \\
\hline 2 & 15 & 8 & 5 & 6 & 13 & 13 \\
\hline 3 & 13 & 10 & 5 & 8 & 10 & 9 \\
\hline 4 & 10 & 11 & 18 & 6 & & \\
\hline 5 & & & 12 & 14 & & \\
\hline 6 & & & 8 & 9 & & \\
\hline 7 & & & 12 & 8 & & \\
\hline 8 & & & 5 & 5 & & \\
\hline 9 & & & 5 & 4 & & \\
\hline 10 & & & 5 & 4 & & \\
\hline 11 & & & 5 & 4 & & \\
\hline 12 & & & 15 & 4 & & \\
\hline 13 & & & 15 & 11 & & \\
\hline 14 & & & 5 & 4 & & \\
\hline Mean & 10.5 & 8.5 & 9.3 & 6.9 & 11.0 & 10.0 \\
\hline
\end{tabular}




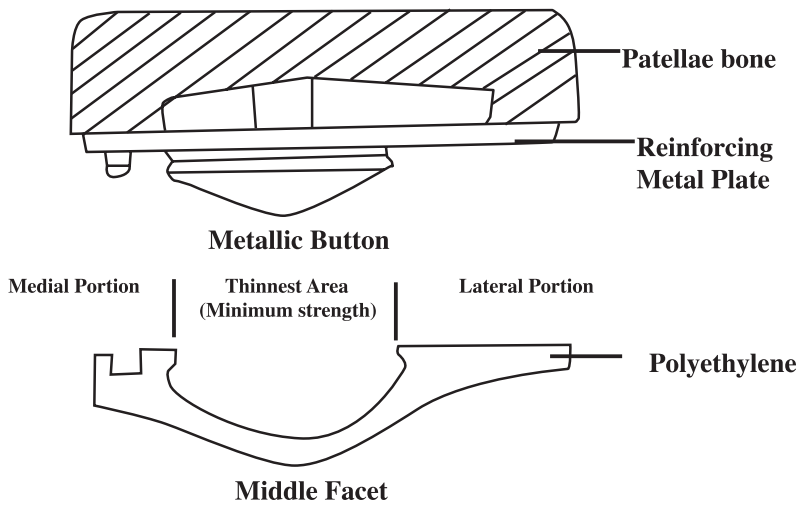

Fig. 5. Variation of the thickness on the cross section of the polyethylene component.

showed polyethylene worn-through on the medial side (Fig. 3B).

\section{Group C-Cantilevering Breakage}

This type of failure involved 4 cases $(12.5 \%)$ of fragmentary breakages mostly in the lateral portion. During the revision, bony ingrowths over the corner of the metal plate were noted (Fig. 4A). We believe the bone ingrowth impinged on the polyethylene rotation. The cause of such breakage was the stress riser in the polyethylene sustaining the load as a cantilever beam when rotated out of the metal-back buttress (Fig. 4B).

Of the 11 knees that were revised primarily for patellar component failure, 6 cases were in group A, 2 cases in group B, and 3 cases in group C.

The alignment measurements of the patellar components in each group using the roentgenogram are summarized in Table 1. There were only
21 roentgenograms available: 4 belonged to group A, 14 to group B, and 3 to group C. Using these roentgenograms, we found that $75 \%(3 / 4)$ of group A, $64.3 \%(9 / 14)$ of group B, and $100 \%(3 / 3)$ of group C showed patellar subluxation displacement and/or tilting. Group A had a larger subluxation displacement (average: $8.5 \mathrm{~mm}$ ) and tilt angle (average: $10.5^{\circ}$ ) than group B (displacement: $6.9 \mathrm{~mm}$; tilt: $\left.9.3^{\circ}\right)$. Group C had the largest subluxation displacement $(10.0 \mathrm{~mm})$ and tilt angle $\left(11.0^{\circ}\right)$, which limited the patellar rotating mobility leading to the cantilevering breakage seen.

\section{Discussion}

The patellar component of the LCS design provides good congruency that reduces contact stress and polyethylene wear. Even so, patellar polyethylene failure was still evident during intermediate follow-up. Two specific factors were considered as the primary causes of the polyethylene failure: misaligned contact surfaces and blockage of rotating mobility.

\section{Misaligned Contact Surfaces}

One of the principal characteristics of the patellar component in the LCS design is congruent anatomic shape, which distributes contact stress evenly while articulating. But, for this to happen, the patellar component also needs to be properly seated in the femoral groove. Because the polyethylene component was of an irregular polyhedron, its tilt or subluxation led to partial contact with the femoral convex surface by its pinnacle or bilateral flanges, resulting in the loss of the geometrical

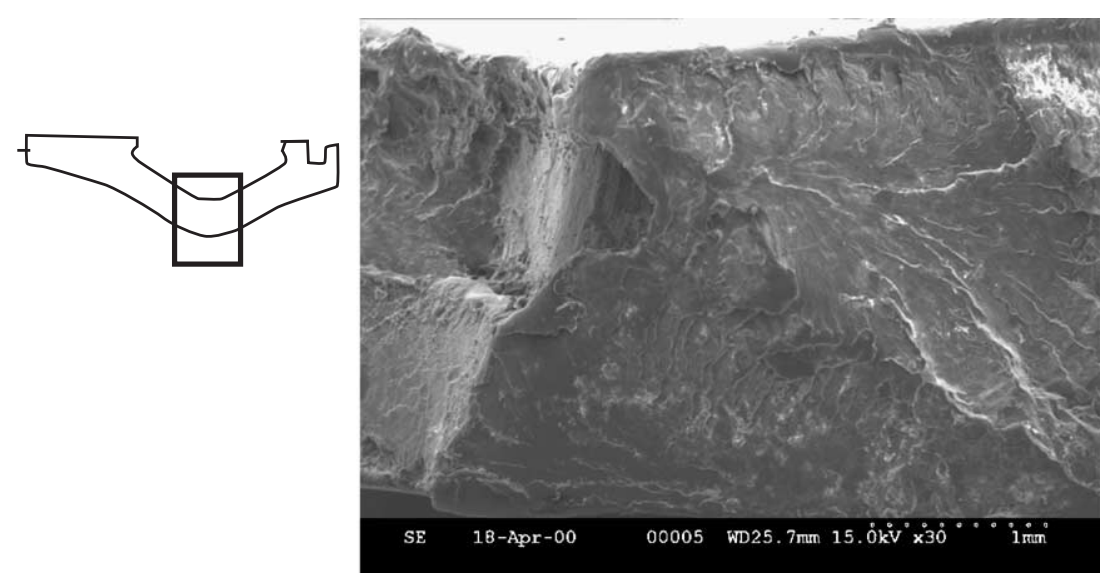

Fig. 6. The SEM photograph of a specimen from group A showing a zip-through split. The section with the thinnest area shows an obvious river pattern which is considered as the crack initiating point. 
congruency and, thus, uneven stress distribution. Both group A and B demonstrated such a problem. Because the patellar component fitted to a shaft of the metallic button settling in the metal baseplate, the thickness of the polyethylene was uneven (Fig.5). The area beneath the button had the minimum thickness, meaning the minimum strength.

When a large subluxation of the patellar component occurred, the pinnacle of the polyethylene, especially at the thinnest part beneath the metallic button, became the only point that had contact with the femoral condyle. The polyethylene would then experience a highly concentrated load on its thinnest part and begin to crack and/or tear. The crack could then propagate toward either the medial or lateral side or both.

The split rupture of group A came with 2 conditions. First, the crack split the polyethylene into 2 symmetrical parts (Fig. 2A). Second, the crack went through the longer, thinner flange but was arrested in the shorter, thicker one (Fig. 2B). The scanning electron microscope photograph in Fig. 6 shows the thinnest point of crack initiation with patterns of striations (to the right of the center) indicating fatigue crack advancement.

If the patellar component is tilted, it will make contact with the femoral condyle on one of its flange. The flange will then take up the majority of the load, leading to the peripheral wear as illustrated by group B. Fig. 7 shows the severe delamination seen around the flange.

Both patellar tilting and subluxation resulted in the misalignment of the patellofemoral joint; it is difficult to single out a one-to-one relationship between either of them and the failure type. The mean tilt angle and subluxation displacement were greater in group A than those in group B (Table 1).
If the cases of normal alignment (tilting $\leqq 5^{\circ}$, displacement $\leqq 5 \mathrm{~mm}$ ) in groups $\mathrm{A}$ and $\mathrm{B}$ were excluded, group A had larger subluxation displacement $(9.7 \mathrm{~mm})$ than group $B(8.9 \mathrm{~mm})$, but had smaller tilting $\left(12.7^{\circ}\right)$ than group B $\left(13.6^{\circ}\right)$. The data seem to suggest that larger subluxation displacement of patellar component results in a split rupture, whereas larger tilting results in peripheral wear.

\section{Blockage of Rotating Mobility}

Another advantage of the LCS design is its rotating mobility, which adjusts the patellar tracking and reduces the shear stress at the bone/implant interface. When the patellar components experienced a large tilt and displacement (group C), the range of the rotating mechanism might become limited. This may cause bony ingrowths at the corner of the metallic baseplate. When rotation was blocked by the bony ingrowths, the polyethylene extended beyond the metal buttress and behaved as a cantilever beam, leading to cantilevering breakage.

Several reports have discussed the dome-shaped polyethylene failure caused by patella tilt and subluxation [7-15]. The metal-backed polyethylene usually failed at locations where there was a higher chance to come in contact with the femoral condyle. Even the symmetrically dome-shaped patellar component could still run into the situation of having a highly concentrated load on the polyethylene. For patellar components with metal backing, the thickness of polyethylene is further reduced and so is its strength $[16,17]$.

Buechel et al reported that the isolated failure rate of rotating-bearing patellar components requiring revision surgery was $0.6 \%$, and there was

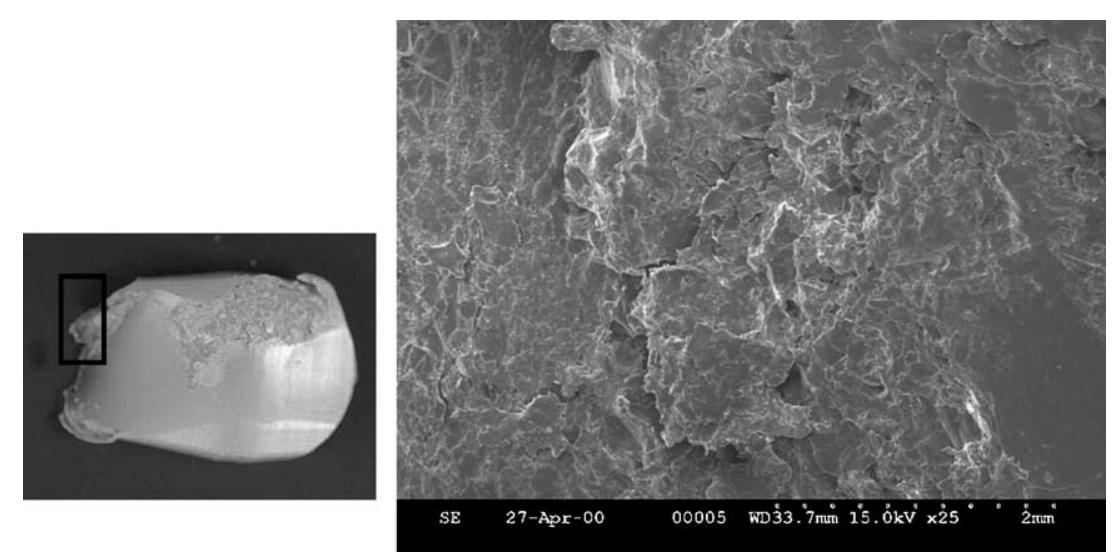

Fig. 7. A large area of delamination on the articulating surface of a patellar component in group B. 
no polyethylene wear-through in their 11-year follow-up [3]. By comparison, the incidence of revision caused by isolated patellar failure in our study was $1.8 \%$ (11/598), whereas our overall failure rate of the LCS design was $5.35 \%$ (32/598). Regarding other types of metal-backed patellar designs, Crites and Berend reported a revision rate of $9.5 \%$ after 10 years [18]. Hsu et al reported a $21 \%$ complication rate, including patellar polyethylene wear in $17 \%$ of patients and patellar subluxation or dislocation in $4 \%$ of patients 3.2 to 6.6 years postoperatively [19]. These clinical findings showed that the LCS rotating patellar design was better than its metal-backed peers. However, the misalignment of the contact surfaces and blockage of the rotating mobility could exacerbate the patellar component failure.

The patellofemoral joint reaction force is influential in polyethylene wear. In our previous study, the total thickness of the patella after the total knee arthroplasty was greater than the preoperative thickness in Chinese patients [20]. The increase of the patellar thickness will cause a higher patellofemoral joint reaction force and thus higher contact pressure [21]. Therefore, increasing the total patellar thickness after total knee arthroplasty could increase the polyethylene wear. This, to some extent, explained for the conundrum of the higher polyethylene failure rate seen in our series than those of other studies $[3,4]$.

We found that severe polyethylene wear sometimes came with yellowish color change in this study. The color change was indicative of progressive oxidation. The shelf life of those components before implantation was less than 2 years and this could have some contribution to the oxidation seen. On the other hand, before the early 1990s the industrial standard sterilization was using $\gamma$ radiation in an air environment [22], which was known to induce a certain level of oxidation of polyethylene as well as reduction of the mechanical toughness.

Low-contact stress patellar components are well designed with a lower rate of failure as compared with other competitive designs. For here, the authors would like to offer the following recommendation based on our clinical findings: the patellar component can be modified to have a flatter metallic button to increase the focal thickness of polyethylene and a dome-shaped polyethylene to reduce the concentration of stress on the pinnacle should subluxation or tilting of the patellar occurs. The authors would also like to point out that surgical technique, although not felt to be a factor in this study, plays an important role in achieving joint alignment, which is contributory to component integrity.

\section{Acknowledgments}

The authors are pleased to acknowledge the financial support of the National Science Council (NSC 92-2314-B-195-001), ROC.

\section{References}

1. Buechel FF, Pappas MJ. The New Jersey LCS knee replacement system biomechanical rationale and comparison of cemented and noncemented results. Contemp Orthop 1987; 14:52.

2. Huang $\mathrm{CH}$, Young $\mathrm{TH}$, Lee YT, et al. Polyethylene failure in New Jersey low-contact stress total knee arthroplasty. J Biomed Mater Res 1998;39:153.

3. Buechel FF, Rosa RA, Pappas MJ. A metal-backed, rotating-bearing patellar prosthesis to lower contact stress: an 11-year clinical study. Clin Orthop 1989;248:34.

4. Sorrells RB. The rotating platform mobile bearing TKA. Orthopaedics 1996;19:793.

5. Gomes LS, Bechtold JE, Gustilo RB. Patellar prostheses positioning in total knee arthroplasty: a roentgenographic study. Clin Orthop 1988;236:72.

6. Bindelglass DF, Cohen JL, Dorr LD. Patellar tilt and subluxation in total knee arthroplasty: relationship to pain, fixation, and design. Clin Orthop 1993;286:103.

7. Rosenberg AG, Andriacchi TP, Barden R, et al. Patellar component failure in cementless total knee arthroplasty. Clin Orthop 1988;236:106.

8. Anouchi YS, Whiteside LA, Kaiser AD, et al. The effects of axial rotational alignment of the femoral component on knee stability and patellar tracking in total knee arthroplasty demonstrated on autopsy specimens. Clin Orthop 1993;287:170.

9. Bayley JC, Scott RD. Further observations on metalbacked patellar component failure. Clin Orthop 1988;236:82.

10. Collier JP, McNamara ME, Surprenant VA, et al. Allpolyethylene patellar components are not the answer. Clin Orthop 1991;273:198.

11. Rand JA. Current concepts review the patellofemoral joint in total knee arthroplasty. J Bone Joint Surg Am 1994;76:612.

12. Stulberg SD, Stuberg BN, Hamati Y, et al. Failure mechanism of metal-backed patellar components. Clin Orthop 1988;236:88.

13. Sutherland CJ. Patellar component dissociation in total knee arthroplasty: a report of two cases. Clin Orthop 1988;228:178.

14. Wasilewski SA, Frankl U. Fracture of polyethylene of patellar component in total knee arthroplasty, diagnosed by arthroscopy. J Arthroplasty 1989; (Suppl):19. 
15. Yoshii I, Whiteside LA, Anouchi YS. The effect of patellar button placement and femoral component design on patellar tracking in total knee arthroplasty. Clin Orthop 1992;275:211.

16. Bayley JC, Scott RD, Ewald FC, et al. Failure of the metal-backed patellar component after total knee replacement. J Bone Joint Surg Am 1988; 70:668.

17. Rader CP, Wittman LR, Eulert J. Results of total knee arthroplasty with a metal-backed patellar component. J Arthroplasty 1996;1 1:923.

18. Crites BM, Berend ME. Metal-backed patellar components-a brief report on 10-year survival. Clin Orthop 2001;388:103.
19. Hsu RWW, Tasi YH, Huang TJ, et al. Total knee arthroplasty: patella resurfacing versus nonresurfacing. J Orthop Surg ROC 1998;15:113.

20. Huang $\mathrm{CH}$, Cheng CK, Liau JJ, et al. Morphometrical comparison between the resected surfaces in osteoarthritic knees and porous-coated anatomic knee prostheses. J Musculoskelet Res 2000;4:39.

21. Hsu HC, Luo ZP, Rand JA, et al. Influence of patellar thickness on patellar tracking and patellofemoral contact characteristics after total knee arthroplasty. J Arthroplasty 1996;1 1:69.

22. Collier JP, Sutula LC, Currier BH, et al. Overview of polyethylene as a bearing material: comparison of sterilization methods. Clin Orthop 1996;333:76. 